\title{
ANÁLISE DOS DETERMINANTES DE DESEMPENHO EM COOPERATIVAS DE CRÉDITO NO BRASIL: UM ESTUDO COM BASE NA INTERMEDIAÇÃO FINANCEIRA E NA PRESTAÇÃO DE SERVIÇOS BANCÁRIOS
}

\author{
Nome \\ Manuela Gonçalves Barros \\ Instituição/Afiliação \\ Universidade Federal de Mato Grosso \\ País \\ Nome \\ Brasil - E-mail: manuelagb@hotmail.com \\ Marcelo Botelho da Costa Moraes \\ Instituição/Afiliação \\ Universidade de São Paulo \\ País \\ Brasil - E-mail: mbotelho@usp.br
}

\section{RESUMO}

Este estudo investigou os determinantes do desempenho das cooperativas de crédito na geração de benefícios aos cooperados. Foram consideradas duas vertentes: uma financeira, relacionada aos benefícios gerados por meio da intermediação financeira, e uma operacional, relacionada aos benefícios gerados pela prestação de outros serviços bancários. Entre outras variáveis indicadas como determinantes específicas de cada vertente, são determinantes comuns nos dois aspectos avaliados as Despesas Administrativas/Total Geral do Ativo e a Imobilização. Destaca-se, ainda, que houve discordância dos efeitos de algumas das variáveis determinantes sobre o desempenho nas vertentes investigadas. Além disso, verificou-se que a Participação da Receita de Prestação de Serviços e a Participação do Resultado de Outras Receitas Operacionais contribuem para uma redução nas Taxas de Juros sobre Empréstimos, o que tem potencial impacto sobre o spread das cooperativas de crédito.

Palavras-chave: Cooperativas de crédito. Desempenho. Intermediação financeira. Prestação de serviços.

\begin{abstract}
This study investigated the determinants of the performance of credit unions in generating benefits for members. Two aspects were considered: one financial, related to the benefits generated through financial intermediation, and one operational, related to the benefits generated by the provision of other banking services. Among other variables indicated as specific determinants of each aspect, the Administrative Expenses/Total of Assets and Fixed Assets are common determinants in the two aspects evaluated. It is also noteworthy that there was disagreement on the effects of some of the determining variables on performance in the investigated areas. In addition, it was found that the Share of Revenue from Services Rendered and the Share of the Result of Other Operating Income contribute to a reduction in Interest Rates on Loans, which has a potential impact on the spread of credit unions.
\end{abstract}

Keywords: Credit unions. Performance. Financial intermediation. Service provision. 


\section{Revista

\section{Introdução}

Cooperativas de crédito são instituições financeiras que se destinam, sobretudo, à prestação de serviços financeiros aos seus associados, por meio do mutualismo, fornecendo serviços de depósitos, empréstimos, financiamentos, entre outros, a um grupo definido por um elo comum. Com o passar do tempo, este elo se tornou menos importante, em parte, devido à formação de agências de crédito na extensão de todo o país ou território de atuação das instituições financeiras para fornecer informação detalhada quanto à solvabilidade dos indivíduos (Goddard et al., 2008).

De forma semelhante às demais instituições financeiras em geral, a atividade das cooperativas de crédito congrega a intermediação financeira e a prestação de serviços bancários, no entanto, sem a finalidade de maximização de lucros. As organizações cooperativas destinam-se a atender aos objetivos sociais e econômicos das pessoas que compõem sua filiação e, conforme (McKillop e Wilson, 2011), o dinheiro excedente gerado pelas atividades de negócios pertencem aos seus membros. Isso porque a destinação desse excedente, depois de feitas as destinações legais obrigatórias, é votada e decidida em Assembleia Geral. Desta forma, conforme colocado por Bauer (2008), os excedentes ou sobras geradas pelas mesmas são retornados aos membros na forma de reinvestimentos nas cooperativas de crédito, na forma de distribuição de sobras para os membros, ou na forma de taxas de juros mais baixas sobre os produtos de crédito.

Diante do fato de que, em geral, as cooperativas são organizações cujo propósito principal é econômico ou comercial e cujos membros aderem por razões econômicas (Barton, 1989), este estudo investigou os determinantes do desempenho das cooperativas de crédito no Brasil considerando dois aspectos distintos relacionados ao cumprimento de seu objetivo principal de geração de benefícios econômicos aos seus membros - um ligado à intermediação financeira e outro ligado à prestação de serviços bancários. A consideração dos dois aspectos sugere a aplicação de dois modelos diferentes para a avaliação do desempenho destas organizações.

Assim, com base nos dois aspectos considerados, buscou-se, responder ao questionamento: Quais são os determinantes do desempenho na intermediação financeira e na prestação de serviços das cooperativas de crédito brasileiras, na perspectiva do beneficiamento dos cooperados? 


\section{Revista

Enquanto a avaliação do desempenho das cooperativas de crédito na perspectiva dos cooperados é pouco explorada pela literatura, os estudos realizados sob esta perspectiva concentraram-se, predominantemente, no volume de operações de crédito praticadas como o principal benefício socioeconômico oferecido aos mesmos. É de se destacar, no entanto, importância da consideração de outros aspectos que impactam a renda dos cooperados, como a prestação de outros serviços bancários e de variáveis relacionadas aos preços praticados por essas organizações, fatores que impactam diretamente o benefício obtido pelos cooperados pelo uso, ou seja, por meio das atividades realizadas junto às cooperativas.

Assim, justifica-se o propósito desta pesquisa pela necessidade de, diante da função econômico-social das cooperativas de crédito, avaliar o desempenho destas organizações considerando o seu propósito original de geração de benefícios econômicos aos cooperados, tanto sob os aspectos da intermediação financeira, quanto dos custos na prestação de serviços - ligada à prestação de outros serviços do Sistema de Pagamentos Brasileiro (SPB).

Um dos motivos que levam à preocupação com o desempenho e eficiência das cooperativas de crédito é a possibilidade de operações ineficientes decorrentes de sua natureza diferenciada e estrutura de governança e institucional peculiar. Além disso, seu potencial de democratização do crédito (Santos, 2013) e de desconcentração da renda e os incentivos à expansão do setor são outros fatores que podem justificar essa preocupação.

\section{Fundamentação Teórica e Empírica}

O desempenho das cooperativas de crédito no Brasil tem sido avaliado em diferentes dimensões, de modo que neste trabalho dá-se ênfase aos autores que buscaram fazer essa avaliação a partir de variáveis financeiras.

Vilela et al. (2007) fizeram uma avaliação do desempenho relativo das cooperativas de crédito rural de São Paulo, no tocante ao seu objetivo de operação, a partir de uma aplicação do método de análise por envoltória de dados (DEA). Os autores utilizaram o ativo total e as despesas administrativas como inputs do modelo e o volume de operações de crédito como output, representando a concessão de crédito e 
demonstraram que as cooperativas que dispunham de maiores volumes de recursos (ativo total) conseguiram obter desempenho superior, na concessão de crédito.

No mesmo sentido, Ferreira et al. (2007) buscaram identificar o desempenho das cooperativas de economia e crédito mútuo de Minas Gerais e os fatores associados à eficiência, considerando o seu papel de "desintermediadora" financeira. A mensuração da eficiência deu-se por meio da Análise Envoltória de Dados (DEA), utilizando como outputs do modelo a variável volume de operações de crédito como principal benefício socioeconômico das cooperativas de crédito, as sobras operacionais, representando o resultado global líquido da cooperativa, e o ativo total como proxy do tamanho da cooperativa. Como inputs do modelo foram utilizados o custo total com empregados, as despesas administrativas e as despesas não administrativas. Como resultado, foram verificados como indicadores determinantes da eficiência nas cooperativas de crédito: a capitalização, o capital em giro, a alavancagem e a geração de rendas.

Bressan et al. (2010) avaliaram a eficiência de custo e a economia de escala de 42 cooperativas de crédito mútuo no estado de Minas Gerais no período de 2001 a 2003 utilizando uma abordagem de fronteira estocástica de custos com dados em painel e uma medida de economia de escala que analisa a proporcionalidade entre a variação dos custos e a variação dos produtos gerados pela cooperativa. As variáveis utilizadas no estudo foram: as operações de crédito, representando o produto gerado pelas cooperativas; a despesa total, representando o custo total; e o ativo permanente e a despesa de pessoal, representando os insumos utilizados pela cooperativa. A partir do modelo apresentado, verificou-se que as variáveis ativo permanente, operações de crédito e despesas de pessoal provocam um aumento no custo total e que as cooperativas estudadas estavam atuando com ineficiência de custo. Concluiu-se, ainda, que o porte das cooperativas não interferiu na medida de eficiência, já que houve uma baixa correlação entre o tamanho da mesma e o escore da eficiência de custo (Bressan et al., 2010).

Como pôde ser verificado, apesar de a atividade das cooperativas de crédito ser semelhante à das demais instituições financeiras, a avaliação do desempenho das mesmas não deve se basear apenas nos mesmos indicadores tradicionalmente utilizados na avaliação de bancos, já que estas não são voltadas para a maximização de valor para o investidor com base no investimento e sim para a geração de valor para o cooperado por meio de seu produto, entendimento que direcionou a realização do presente estudo. 


\section{Revista

Nessa vertente, melhor será o desempenho da cooperativa no cumprimento de seu objetivo à medida que estas instituições tiverem maior impacto sobre a renda do cooperado, especialmente por meio da intermediação financeira e da prestação de outros serviços bancários, já que o objetivo dos seus membros se afiliarem à organização é, fundamentalmente, econômico. A intermediação financeira consiste na captação e na aplicação de recursos, sendo que o resultado está associado ao spread praticado pela cooperativa, enquanto a prestação de serviços consiste no atendimento aos clientes e principais operações financeiras dentro do Sistema de Pagamentos Brasileiro (SPB) a preços mais vantajosos.

\subsection{Cooperativas de crédito e a geração de benefícios aos cooperados}

Diferentemente das organizações orientadas para o investidor (IOF's - Investor's Oriented Firms), as quais têm por objetivo a maximização do retorno sobre o investimento, as cooperativas, que são de propriedade e controle dos cooperados (Barton, 1989), têm como finalidade principal a geração de benefícios ao cooperado por meio de benefícios econômicos encontrados sob a forma cooperativada. O que seria o lucro líquido nas IOF's, nas cooperativas retorna para os seus usuários ou patronos na proporção de suas atividades com a cooperativa, ou seja, os benefícios são distribuídos com base no uso (Barton, 1989).

Para Barton (1989), algumas cooperativas podem fornecer benefícios de valor social, os quais incluem quaisquer resultados não econômicos, entre eles o bem estar do cooperado por estar envolvido com outros em busca de um propósito comum ou mesmo por atuar na cooperativa como proprietário. O autor considera que os benefícios não econômicos são importantes, mas que se uma cooperativa não atende os propósitos econômicos, no longo prazo elas serão incapazes de ainda fornecer benefícios sociais, já que o resultado será a liquidação da organização ou mesmo sua reorganização devido à necessidade econômica.

Com base em Emmons e Schmid (2000), as cooperativas de crédito são capazes de gerar benefícios econômicos aos cooperados por meio da política de preços e, também, da geração de sobras. Conforme os autores, a política de preços está relacionada a um menor spread em relação às demais instituições financeiras, por meio do fornecimento de maiores taxas de retorno aos depósitos captados e de taxas de juros mais baixas pelos 


\section{Revista \\ UNEMAT de \\ Contabilidade}

v. 9, n. 18,2020

empréstimos concedidos. Por outro lado, a geração de sobras como benefício econômico está relacionada à distribuição das sobras aos cooperados ou patronos elegíveis (Barton, 1989; Emmons \& Schmid, 2000). Barton (1989) inclui entre os benefícios econômicos gerados aos cooperados os serviços prestados pelas cooperativas e, ainda, os próprios salários pagos aos funcionários. Nas cooperativas de crédito os serviços prestados incluiriam outros serviços bancários, além daqueles de intermediação financeira.

Com relação aos serviços de intermediação financeira, conforme apontado por Bressan (2009), a cooperativa de crédito é uma fonte de recursos não somente para consumidores de crédito, mas também para aplicadores. Dessa forma, enquanto alguns cooperados podem usar estas cooperativas apenas a fim de realizar aplicações de recursos financeiros, seja por depósitos à vista ou a prazo; enquanto outros podem utilizá-las apenas como fonte de consumo de crédito, captando empréstimos ou financiamentos da cooperativa (Bressan, 2009). Uma terceira possibilidade é a atuação como aplicador e captador de recursos ao mesmo tempo.

Com relação à existência desses diferentes usuários cooperados, Fried et al. (1993) colocam que ao aceitar poupanças de membros a cooperativa de crédito tem algumas características de cooperativas produtoras, enquanto que ao fornecer empréstimos para membros têm algumas características de cooperativas de consumo, o que sugere que os interesses dos membros poupadores estão em conflito com os interesses dos membros mutuários. Para os autores, esta falta de unanimidade torna os modelos cooperativos de produtores e os modelos cooperativos de consumo - ambos os quais assumem unanimidade nos objetivos dos membros e também um grupo de não-membros para explorar no esforço para atingir esses objetivos - modelos inapropriados sobre o comportamento das cooperativas de crédito.

Assim, uma vez que os interesses dos membros poupadores são nem mais e nem menos importantes que os interesses dos membros mutuários, é desejável que se evite atribuir, a priori, pesos para serviços de poupança e para serviços de empréstimos que uma cooperativa de crédito oferece aos seus membros (Fried et al., 1993).

Existem modelos sobre o comportamento de cooperativas de crédito que colocam forte ênfase sobre como o equilíbrio na distribuição de benefícios entre seus membros mutuários e poupadores é alcançado, alguns dos quais apresentados por McKillop e Wilson (2011). Conforme o autor, a abordagem de Taylor (1971), a qual foca na extensão 
para a qual as cooperativas de crédito balanceiam os interesses de membros poupadores e captadores, cria um problema; isso porque, enquanto os membros poupadores querem o maior retorno possível sobre o capital investido, os membros captadores querem o menor custo possível no consumo de crédito.

Taylor (1971) considera três cenários para explorar potenciais conflitos entre membros de uma cooperativa de crédito: 1) a cooperativa neutra; 2) a cooperativa dominada por tomadores de recursos; e 3) a cooperativa dominada por poupadores de recursos. Enquanto nos dois últimos cenários devem predominar os interesses dos respectivos membros dominadores, no primeiro cenário os interesses de nenhum dos membros dominam. Seguindo esse raciocínio, uma interpretação seria que cada tipo de cooperativa de crédito precisaria buscar as alternativas que levassem ao maior benefício dos cooperados dominadores em detrimento dos demais, em busca de um melhor desempenho no atendimento aos interesses dos cooperados.

Assume-se, no entanto, seguindo a abordagem de Fried et al. (1993), que a cooperativa de crédito terá um melhor desempenho na geração de benefícios aos cooperados, em termos de intermediação financeira, se ela buscar o melhor interesse dos dois tipos de membros, ou seja, buscar o maior retorno para os aplicadores e a menor taxa de captação para os mutuários de uma forma mais neutra, maximizando o benefício total dos cooperados. Para o autor, essa neutralidade é menos provável à criação de incentivos para as cooperativas de crédito desencorajarem a participação de novos membros e, portanto, ajuda a manter a vitalidade da instituição.

Ainda com relação à intermediação financeira, toma-se que quanto mais operações de aplicação e captação a cooperativa de crédito tiver com seus cooperados, ou seja, quanto mais atos cooperativos ela realizar, melhor será o seu desempenho na geração de benefícios aos mesmos, já que tanto a distribuição de sobras quanto a distribuição de benefícios através dos serviços prestados ocorrem com base na quantidade de atividade dos cooperados com a organização. Essa ideia corrobora com Fried et al. (1993). Ainda, entende-se que quanto menor for a dependência da cooperativa em relação a outras organizações e, portanto, quanto maior for sua capacidade de se manter sozinha, sem ter que recorrer a outras instituições financeiras, mais ela poderá utilizar seus recursos em benefício dos cooperados. 


\section{Revista

No que tange ao desempenho das cooperativas de crédito na prestação de serviços aos cooperados, apesar de a aplicação e a captação de recursos serem os principais serviços fornecidos pelas cooperativas aos cooperados como forma de beneficiá-los, estas podem oferecer diversos outros serviços como de cobrança, custódia, transferência de fundos, abertura de contas, entre outros. E uma vez que o objetivo destas organizações é a geração de benefícios por meio da prestação de serviços, a avaliação do desempenho deve considerar esse aspecto.

Fried et al. (1993) mensuram a performance de uma amostra de cooperativas de crédito dos EUA quanto à capacidade destas de obterem a máxima quantidade de serviços aos cooperados, dados os inputs disponíveis. Os autores defendem que o considerável maior espaço encontrado nas empresas de sua amostra para a melhoria da dimensão de qualidade - considerada como a quantidade de empréstimos e depósitos fornecidos - do que para as dimensões de preço e variedade dos serviços financeiros prestados implica que as cooperativas de crédito podem melhorar seu desempenho obtendo mais membros do seu quadro de membros potenciais e obtendo mais contas por membro. Dessa forma, poderia ser assumido que o aumento no número de cooperados e na quantidade de empréstimos e depósitos por cooperados seria uma boa medida de desempenho.

Goddard et al. (2008), motivados pelo aumento significativo das receitas não provenientes de juros, investigaram o impacto da diversificação da receita sobre o desempenho financeiro para o período de 1993 a 2004 utilizando os dados publicados por cooperativas de crédito dos Estados Unidos. Os autores verificaram que nas cooperativas de crédito maiores o efeito positivo de exposição direta para as medidas de retorno não ajustadas ao risco (ROE e ROA) supera o efeito negativo de exposição indireta, já que elas têm sido capazes de melhorar seus retornos não ajustados ao custo de assumir algum risco adicional. Estas, portanto, podem ser encorajadas a explorar novas oportunidades de produtos em torno de sua principal especialidade. Já nas cooperativas de crédito menores (cerca de $83 \%$ da amostra) ocorre o inverso e estas deveriam evitar diversificação e continuar a operar como simples instituições de poupança e empréstimos (Goddard et al., 2008).

\section{Metodologia}


Inicialmente, são apresentados os principais aspectos concernentes à amostra estudada, seguidos da apresentação e descrição das proxies de desempenho na intermediação financeira e de desempenho de custos na prestação de serviços. Posteriormente, foram apresentadas as etapas de investigação dos determinantes do desempenho sob os dois aspectos investigados.

\subsection{Amostra e método}

A base de dados inicial é composta pelas cooperativas de crédito componentes da base de dados do Banco Central do Brasil que apresentaram operações em todo o período de 2007 a 2014, totalizando 1.068 cooperativas de crédito. A partir da base inicial foram eliminadas aquelas que não possuíam as informações necessárias para o cálculo dos indicadores selecionados para todo o período, a fim de se obter uma amostra balanceada com dados em painel. Nessa etapa, foram excluídas 282 cooperativas, restando uma amostra de 786 organizações.

Posteriormente, foram eliminadas aquelas cooperativas que apresentavam características de outlier em algum momento do período, a partir da análise da amplitude interquartil, utilizada devido à característica de não normalidade dos dados analisados da amostra em estudo. Isso resultou na obtenção da amostra final de 353 cooperativas de crédito, para o período de 8 anos, totalizando 2.824 observações com dados longitudinais, válidas para a análise de regressão. O processo de composição da amostra foi resumido no Quadro 1.

\section{Quadro 1 - Composição da amostra}

Amostra inicial de cooperativas de crédito 
Cooperativas de crédito da base de dados do Banco Central com operações em todo o período

(-) Cooperativas sem dados disponíveis para cálculo dos indicadores

(=) Amostra inicial balanceada para a aplicação de dados em painel

(-) Cooperativas com características de outlier (1,5 a amplitude interquartil)

(=) Amostra após a eliminação de outliers

(-) Cooperativas que apresentaram valores negativos

(-) Cooperativas que apresentaram valor 0 (zero) para a variável Participação da Receita de Prestação de Serviços

Na subseção 3.2 são apresentadas e descritas as variáveis que traduzem o desempenho das cooperativas estudadas sob a ótica da pesquisa, considerando a atividade de intermediação financeira e a atividade de prestação de serviços e na seção 4 parte-se para a análise dos resultados quanto aos determinantes do desempenho.

\subsection{Descrição das variáveis de desempenho}

Considerando a proposta de avaliação do desempenho das cooperativas de crédito, nesta seção são apresentadas e discutidas as proxies de desempenho utilizadas para esta finalidade.

\subsubsection{Desempenho na intermediação financeira}

As variáveis utilizadas na avaliação do desempenho na atividade intermediação financeira, relacionam-se à capacidade da cooperativa de fornecimento dos serviços de empréstimos e depósitos aos cooperados a preços mais vantajosos e, ao mesmo tempo, não perder de vista a continuidade da organização. Assim, são apresentadas as seguintes proxies como variáveis relevantes para a avaliação de desempenho:

- Taxa de Juros sobre Empréstimos: 
Renda de Operações de Crédito

Operações de Crédito

- Taxa de Juros sobre Depósitos:

Despesa de Captação

Depósitos à Vista + Depósitos sob aviso + Depósitos a Prazo + Obrigações por Depósitos Especiais e de Fundos e Programas

- Volume de Operações de Crédito com Cooperados:

$\frac{\text { Operações de Crédito }}{\text { Total Geral do Ativo }}$

- Volume de Captações de Depósitos com Cooperados:

$$
\frac{\text { Depósitos }}{\text { Total Geral do Ativo }}
$$

- Resultado Bruto da Intermediação Financeira:

Resultado Bruto da Intermediação Financeira

Total Geral do Ativo

O fato de os cooperados já serem associados à sua unidade de crédito, capitalizando-a continuamente, facilita a redução do spread da cooperativa e a melhor exploração de sua capacidade operacional (Ferreira et al., 2007). Dessa forma, neste estudo, seguindo Fried et al. (1993), Wheelock e Wilson (2013) e Frame et al. (2003), utilizou-se como proxies da política de preços na atividade de intermediação financeira das cooperativas de crédito as Taxas de Juros sobre Empréstimos aos cooperados e as Taxas de Juros sobre Depósitos dos cooperados.

A busca por taxas de juros sobre depósitos mais altas e por taxas de juros sobre empréstimos mais baixas em benefício do cooperado pode ser vista como um reflexo da diferença de interesses entre membros aplicadores e captadores de recursos. Isso porque enquanto os primeiros buscam uma maior remuneração pelo capital investido na forma de depósitos e de integralização de capital, os captadores de recursos buscam uma menor taxa de captação de recursos. Assume-se, desta forma, que quanto maior for a Taxa de 
Juros sobre Depósitos e quanto menor for a Taxa de Juros sobre Empréstimos, mais eficiente será a cooperativa.

Essa ideia pode ser corroborada pela a afirmação de Rubin et al. (2013) de que, entre os modelos recentes de especificação do benefício para o membro da cooperativa sumarizados em seu trabalho, o modelo de Smith et al. (1981, p. 521), que "define o benefício do membro captador (poupador) como a diferença entre as taxas de mercado sobre os empréstimos (poupança) vezes o volume daqueles empréstimos (poupança)" parece ser o mais consistente com os princípios da cooperativa de crédito de fornecer empréstimos de baixo custo e depósitos de alto rendimento para o associado.

No que tange à aplicação e captação de recursos, principais serviços fornecidos pela cooperativa, os quais devem ser maximizados em benefício dos cooperados, estas são representadas pelos indicadores Volume de Operações de Crédito com Cooperados e Volume de Captações de Depósitos com Cooperados, de forma que quanto maiores estes forem, melhor é a cooperativa em sua autossuficiência.

A variável Volume de Operações de Crédito (Fried et al., 1993; Ferreira et al., 2007; Vilela et al., 2007; Bressan et al., 2010; Silva et al., 2013; Wheelock; Wilson, 2013; Glass et al.; 2010; Cook; Bala, 2007) é comumente utilizada como variável do tipo output nos estudos que avaliam a eficiência de cooperativas de crédito, os quais, em geral a tratam como o principal produto fornecido por essas organizações. Também no presente estudo essa variável foi observada.

Seguindo Fried, Lovell e Eeckaut (1993) e Cook e Bala (2007), que utilizam o Volume de Captações com Depósitos como variável do tipo output na avaliação de eficiência em cooperativas de crédito, este estudo utiliza esta variável como proxy do volume de atividades de captação com cooperados, adotando uma abordagem de produção na avaliação de desempenho, pela qual os depósitos são considerados um produto fornecido aos clientes. Quanto maior a quantidade de depósitos realizados por cooperados, maior benefício gerado ao cooperado.

A variável Resultado Bruto da Intermediação Financeira representa a capacidade da cooperativa de gerar de resultados positivos para a organização através da atividade de intermediação financeira. Esse entendimento da capacidade de geração de sobras como fator imprescindível para a manutenção da atividade da cooperativa, apesar de não ser o foco principal destas organizações, é corroborado por Ferreira, Gonçalves e Braga (2007). 


\section{Revista

Entende-se que a cooperativa precisa ser administrada visando à obtenção de resultados positivos, tais que lhe permitam a manutenção de sua atividade. Desta forma, o Resultado Bruto da Intermediação Financeira é utilizado por contribuir para a geração de sobras, as quais, conforme McKillop e Wilson (2011), pertencem aos cooperados e sua alocação pode tomar um número de formas que incluem: a alocação entre os membros na proporção de suas transações; o desenvolvimento de serviços comuns que beneficiem todos os membros; ou o desenvolvimento do negócio da cooperativa de crédito.

Ressalta-se que todas as variáveis de volume utilizadas neste estudo foram divididas pela conta Ativo Total pelo fato deste trabalho ter por objetivo trabalhar apenas com indicadores financeiros e para reduzir o efeito tamanho sobre as mesmas.

Esse modelo diferencia-se dos demais apresentados na literatura no Brasil por considerar como produtos gerados pelas cooperativas de crédito não apenas o volume de operações de crédito, como tem sido feito em alguns modelos na literatura nacional, mas também o volume de depósitos, como indicadores relacionados à prestação de serviços pela organização. Isso porque os membros das cooperativas se associam às mesmas por motivações econômicas e, portanto, quanto mais atividades de captação e de aplicação de recursos forem realizadas com os cooperados, indica-se ser maior a geração de benefícios aos mesmos.

Conforme foi colocado, são também utilizadas como produtos gerados pelas cooperativas as taxas de juros sobre a captação e aplicação oferecidas pelas cooperativas, como proxy da política de preços, sem desconsiderar a necessidade de geração de resultados positivos para a organização.

\subsubsection{Desempenho na Prestação de Serviços}

Para a avaliação do desempenho na prestação de serviços, deve ser considerada a capacidade da cooperativa de crédito de prestar outros serviços bancários, semelhante ao que ocorre nas agências bancárias, gerando maiores receitas para a contribuição na geração de sobras. Para esta análise, foi utilizada a proxy:

- Receita de Prestação de Serviços pela Receita Total:

Receita de Prestação de Serviços

Receita Total 
Para Bressan et al. (2011), a importância da receita de prestação de serviços reside no fato de que quanto maior a relação entre prestação de serviços e despesas administrativas, maior é a eficiência da instituição.

No estudo de Matias et al. (2014) o aumento na geração de rendas de prestação de serviços, como as tarifas cobradas pela administração de recursos, por serviços de conta corrente, por serviços de recebimento ou por outros serviços bancários, representa um importante fator, não apenas para melhorar a eficiência financeira da cooperativa, mas também para promover o cumprimento da finalidade da mesma. Assume-se, portanto, para o presente estudo, que quanto maior a participação da receita de prestação de serviços na receita total, melhor será o desempenho da cooperativa.

Dado que nos balancetes divulgados pelo Banco Central a conta de Receita de Prestação de Serviços não é detalhada, não foi possível avaliar detalhadamente o desempenho da organização na prestação de serviços devido à grande variedade de possibilidades de fornecimento de serviços. Também, a falta de dados relativos ao número de cooperados para todas as cooperativas em estudo não permitiu o uso dos mesmos na avaliação. No entanto, entende-se que a minimização dos custos na prestação destes serviços, é um dos fatores preponderantes para que organização seja capaz de gerar mais serviços e a um menor custo para os cooperados.

Conforme Bressan et al. (2011), o indicador de receita de prestação de serviços em relação às despesas administrativas é relevante ainda na determinação da probabilidade de insolvência das cooperativas da amostra estudada. Além disso assumese que maiores receitas de prestação de serviços decorrem de uma maior quantidade de serviços prestados.

Desta forma, dado o problema de pesquisa, neste trabalho o modelo de avaliação de desempenho relacionado à prestação de serviços propõe proxies relevantes para a avaliação do desempenho das cooperativas na prestação de outros serviços bancários que são variáveis contábeis relacionadas aos mesmos, contribuindo para a literatura nacional quanto à avaliação de eficiência na prestação de serviços bancários a baixos custos.

\subsection{Etapas para a investigação dos determinantes do desempenho}


Os determinantes do desempenho na atividade de intermediação financeira e na atividade de prestação de serviços bancários das cooperativas foram verificados a partir da avaliação da significância de indicadores financeiros comumente utilizados para a avaliação da atividade bancária sobre as proxies de desempenho definidas para os dois modelos desenvolvidos neste estudo. As significâncias foram obtidas por análises de regressão com dados em painel e as proxies de desempenho definidas na seção 3.2 foram utilizadas como variáveis dependentes nas regressões com dados em painel, enquanto os indicadores financeiros da atividade bancária foram as variáveis.

Inicialmente, foram calculados 31 indicadores financeiros considerados relevantes, os quais tiveram sua formulação adaptada ao plano de contas do Balancete das Cooperativas de Crédito. Os mesmos são apresentados a seguir: Capitalização, Alavancagem, Imobilização, Captação por Floating, Exigibilidades Tributárias e Trabalhistas, Aplicações em Operações de Crédito, Aplicações em Tesouraria, Cobertura com Serviços, Custo de Captação, Custo Administrativo, Participação do Resultado de Outras Receitas Operacionais, Geração Operacional de Rendas, Eficiência Operacional, Margem Operacional, Créditos Não Problemáticos, Inadimplência, Insolvência, Provisionamento, Comprometimento do Patrimônio Líquido Ajustado, Comprometimento do Patrimônio Líquido Seco, Captação por Depósitos a Vista e Poupança, Captação por Depósitos a Prazo, Participação das Receitas de Operação de Crédito e Arrendamento Mercantil, Participação do Resultado de Tesouraria, Spread, Liquidez Geral, Descasamento Ativo, Descasamento Passivo, Despesas Administrativas/Total Geral do Ativo, Sobras Líquidas/Total Geral do Ativo, e Rentabilidade do Ativo.

Calculados os indicadores, foi analisada a multicolinearidade dos dados, considerando as variáveis dependentes e as candidatas a variáveis independentes, sendo que destas últimas foram eliminadas as que apresentaram correlação superior a $|0,80|$. Para isso, optou-se pela utilização do coeficiente de correlação de Spearman, uma vez que para algumas variáveis não foi verificada normalidade. Assim, foram eliminados 17 indicadores por potenciais problemas de colinearidade. Posteriormente, o teste VIF (Variance Inflation Factor) corrobora a ausência de multicolinearidade.

Ressalta-se que entre as variáveis independentes testadas para o modelo de desempenho na intermediação financeira foi incluída a variável dependente do modelo de 
prestação de serviços e, da mesma forma, entre as variáveis independentes testadas no modelo de desempenho na prestação de serviços foram incluídas as variáveis dependentes do modelo de desempenho na intermediação financeira.

Quadro 2 - Fórmulas dos indicadores não correlacionados

\begin{tabular}{|c|c|}
\hline Indicador & Fórmula de cálculo \\
\hline Capitalização & (Patrimônio Líquido) / (Circulante e Exigível a Longo Prazo) \\
\hline Imobilização & (Permanente) / (Patrimônio Líquido) \\
\hline $\begin{array}{l}\text { Captação por } \\
\text { Floating }\end{array}$ & $\begin{array}{l}\text { (Depósitos à Vista + Cobrança e Arrecadação de Tributos e Assemelhados) } \\
\text { / (Circulante e Exigível a Longo Prazo) }\end{array}$ \\
\hline $\begin{array}{l}\text { Exigibilidades } \\
\text { Tributárias e } \\
\text { Trabalhistas }\end{array}$ & $\begin{array}{l}\text { (Outras obrigações Sociais e Estatutárias + Outras obrigações Fiscais e } \\
\text { Previdenciárias) / (Circulante e Exigível a Longo Prazo) }\end{array}$ \\
\hline $\begin{array}{l}\text { Aplicações em } \\
\text { Tesouraria }\end{array}$ & $\begin{array}{l}\text { (Aplicações Interfinanceiras de Liquidez + Títulos e Valores Mobiliários e } \\
\text { Instrumentos Financeiros Derivativos) / (Total Geral do Ativo - Relações } \\
\text { Interdependências - Permanente) }\end{array}$ \\
\hline $\begin{array}{l}\text { Participação do } \\
\text { Resultado de } \\
\text { Outras Receitas } \\
\text { Operacionais }\end{array}$ & $\begin{array}{l}\text { (Outras Receitas Operacionais - Outras Despesas Operacionais) / (Rendas } \\
\text { de Operações de Crédito + Rendas de Aplicações Interfinanceiras de } \\
\text { Liquidez + Renda com Títulos e Valores Mobiliários e Instrumentos } \\
\text { Financeiros Derivativos + Rendas de Prestação de Serviços + Rendas de } \\
\text { Participações - Despesas de Participações + Outras Receitas Operacionais } \\
\text { - Outras Despesas Operacionais) }\end{array}$ \\
\hline $\begin{array}{l}\text { Eficiência } \\
\text { Operacional }\end{array}$ & $\begin{array}{l}\text { (Renda de Operações de Crédito + Rendas de Aplicações Interfinanceiras } \\
\text { de Liquidez + Renda com Títulos e Valores Mobiliários e Instrumentos } \\
\text { Financeiros Derivativos - Despesas de Captação - Despesas de Obrigações } \\
\text { por Empréstimos e Repasses - Despesas com Títulos e Valores Mobiliários } \\
\text { e Instrumentos Financeiros Derivativos + Rendas de Prestação de Serviços) } \\
\text { / (Despesas Administrativas) }\end{array}$ \\
\hline $\begin{array}{l}\text { Margem } \\
\text { Operacional }\end{array}$ & $\begin{array}{l}\text { (Rendas com Títulos e Valores Mobiliário e Instrumentos Financeiros } \\
\text { Derivativos + Rendas de Prestação de Serviços + Rendas de Participações } \\
\text { - Despesas de Participações - Despesas Administrativas - Outras Despesas } \\
\text { Operacionais)/ (Rendas de Operações de crédito + Renda de Aplicações } \\
\text { Interfinanceiras de Liquidez + Renda com Títulos e Valores Mobiliários e } \\
\text { Instrumentos Financeiros Derivativos + Rendas de Prestação de Serviços + } \\
\text { Rendas de participações - Despesas de Participações + Outras Receitas } \\
\text { Operacionais - Outras Despesas Operacionais) }\end{array}$ \\
\hline Inadimplência & $\begin{array}{l}\text { (Operações de Risco Nível B, C, D) / (Classificação da Carteira de } \\
\text { Créditos) }\end{array}$ \\
\hline Insolvência & $\begin{array}{l}\text { (Operações de Risco Nível E, F, G, H) / (Classificação da Carteira de } \\
\text { Créditos) }\end{array}$ \\
\hline $\begin{array}{l}\text { Captação por } \\
\text { Depósitos a Prazo }\end{array}$ & (Depósitos a Prazo) / (Circulante e Exigível a Longo Prazo) \\
\hline
\end{tabular}




\begin{tabular}{|l|l|}
\hline \multicolumn{1}{|c|}{ Indicador } & \multicolumn{1}{c|}{ Fórmula de cálculo } \\
\hline $\begin{array}{l}\text { Descasamento } \\
\text { Passivo }\end{array}$ & $\begin{array}{l}\text { (Depósitos Interfinanceiros + Obrigações por Operações Compromissadas } \\
\text { + Relações Interfinanceiras + Obrigações por empréstimos e Repasses + } \\
\text { Instrumentos Financeiros Derivativos) / (Total Geral do Ativo) }\end{array}$ \\
\hline $\begin{array}{l}\text { Despesas } \\
\text { Administrativas } \\
\text { pelo Ativo Total }\end{array}$ & (Despesas Administrativas) / (Total Geral do Ativo) \\
\hline $\begin{array}{l}\text { Rentabilidade do } \\
\text { Ativo }\end{array}$ & $\begin{array}{l}\text { (Contas de Resultado Credoras-Contas de Resultado Devedoras) / (Total } \\
\text { Geral do Ativo-Relações Interdependências-Permanente) }\end{array}$ \\
\hline
\end{tabular}

Fonte: Dados da pesquisa

Para o desenvolvimento dos modelos de regressão com dados em painel foram aplicadas as três abordagens mais comuns: modelo de efeitos fixos, modelo de efeitos aleatórios e o Pooled Ordinary Least Square (POLS) (Fávero et al., 2009). Os modelos foram aplicados para cada uma das variáveis definidas como outputs e, para a análise dos resultados, foram considerados os testes de Breusch-Pagan, Hausman e o teste de diferença dos interceptos de grupos (adaptação do teste de Chow), os quais permitem a escolha do modelo mais adequado. Na seção a seguir estão apresentados os resultados dos testes realizados para cada variável output de ambos os modelos de avaliação de eficiência na intermediação financeira e na prestação de serviços.

\section{Resultados e Análise de Resultados}

\subsection{Determinantes do Desempenho na Intermediação Financeira}

Para cada uma das variáveis dependentes sugeridas neste trabalho para a avaliação de desempenho na intermediação financeira, verificou-se pelo teste de Chow que foi rejeitada a hipótese nula de que "os grupos têm um intercepto comum". Pelo teste de Breusch-Pagan verificou-se que a variância dos resíduos rejeita a hipótese nula de que a "variância do erro de unidade-específica $=0$ ", de modo que o modelo POLS não é indicado, conforme Fávero et al. (2009). O teste de Hausman também rejeita a hipótese nula de que "as estimativas GLS são consistentes", indicando que o modelo de efeitos aleatórios não é indicado. Neste caso, conforme destaca Wooldridge (2011), rejeitar a hipótese nula do teste de Hausman pode indicar que, ou as estimativas de efeitos aleatórios e as de efeitos fixos são suficientemente próximas ao ponto de que não importa 
qual será usada, ou que a variância amostral é tão grande nas estimativas de efeito fixo que não se pode concluir as diferenças praticamente significantes são, de fato, estatisticamente significantes.

Assim, considerando a análise anterior e o indicativo de Wooldridge (2011) de que o modelo de efeitos fixos é preferível para tratamento de dados populacionais, enquanto o modelo de efeitos aleatórios se aplica a amostras aleatórias, foi aplicado o modelo de efeitos fixos em todas as regressões desenvolvidas para este modelo.

Foram indicadas como determinantes do desempenho nas cooperativas as variáveis significativas a $99 \%$ de significância nos resultados das regressões e que influenciaram as variáveis dependentes com o sinal adequado aos objetivos da cooperativa. Nesse sentido, por exemplo, quanto menor fosse o output taxa de juros sobre empréstimos, mais eficiente seria a cooperativa e, portanto, foram definidas como inputs as variáveis que afetaram o output com sinal negativo.

Após a análise dos resultados de cada painel, para cada variável dependente foi rodado um novo modelo no qual foram omitidas as variáveis com nível de significância menor do que $99 \%$. Os resultados estão apresentados nos quadros 3 a 8 , a seguir.

A variável Taxa de Juros sobre Empréstimos (1) deve ser analisada considerando que ela leva a um melhor desempenho quanto menor for a sua magnitude, indicando que os cooperados estão captando recursos a taxas de juros mais baixas. Os resultados da regressão para essa variável são apresentados no Quadro 3, a seguir: 
Quadro 3 - Regressão Desempenho na Intermediação Financeira: Taxa de Juros sobre Empréstimos

\begin{tabular}{lcccc}
\hline \multicolumn{1}{c}{ Variáveis } & Coeficiente & P-valor & Sinal & Sig. \\
\hline Constante & $9,76655 \mathrm{e}+09$ & 0,6664 & & \\
Participação do Resultado de Outras Receitas & $-0,110455$ & $<0,0001$ & - & $* * *$ \\
Operacionais & & & & \\
Margem Operacional & 0,100818 & $<0,0001$ & + & $* * *$ \\
Inadimplência & 0,0351485 & $<0,0001$ & + & $* * *$ \\
Insolvência & 0,508263 & $<0,0001$ & + & $* * *$ \\
Captação por Depósitos a Prazo & $-0,0700636$ & $<0,0001$ & - & $* * *$ \\
Descasamento Passivo & $-0,351679$ & $<0,0001$ & - & $* * *$ \\
Despesa Administrativa pelo Ativo Total & 2,40137 & $<0,0001$ & + & $* * *$ \\
Participação Receita de Prestação de Serviço & $-0,21982$ & $<0,0001$ & - & $* * *$ \\
R-quadrado & $\mathbf{0 , 8 8 8 3 4 9}$ & & & \\
P-valor(F) & $\mathbf{0 , 0 0 0 0 0 0}$ & & & \\
N (quantidade de cooperativas) & $\mathbf{3 5 3}$ & & & \\
\hline
\end{tabular}

Verifica-se que a Participação do Resultado de outras Receitas Operacionais, a Captação por Depósitos a Prazo, o Descasamento Passivo e a Participação da Receita de Prestação de Serviço estão negativamente relacionados a uma redução na taxa de juros sobre empréstimos. Tendo influenciado a variável dependente com o sinal adequado (negativo) em termos de beneficiamento econômico dos cooperados, aquelas foram analisadas, conforme apresentado a seguir, e confirmadas quanto a serem determinantes do desempenho na intermediação financeira.

A indicação da Captação por Depósitos a Prazo como determinante do desempenho pode ser justificada pelo fato de que os recursos dos poupadores são a fonte de custo mais baixo para os recursos emprestados, de modo que um aumento nesse tipo de captação reduziria as taxas cobradas por empréstimos (Taylor, 1971). Por outro lado, a Participação do Resultado de Outras Receitas Operacionais e a Participação das Receitas de Prestação de Serviços também contribuem para essa redução, o que ressalta o impacto e a importância da diversificação da receita nas operações da cooperativa.

Quanto ao Descasamento Passivo, este indica o quanto a cooperativa está deixando de transacionar com os próprios cooperados, captando recursos de terceiros e deixando, assim, de beneficiar os mesmos de forma direta através de seus serviços. No entanto, esse tipo de captação também é fonte para o fornecimento de mais empréstimos, que, em volume, reduzem as taxas cobradas. 
O Quadro 4, a seguir, apresenta os resultados da regressão para a variável Taxa de Juros sobre Depósitos (2), que leva a um melhor desempenho quanto maior for o seu valor, o qual indicaria uma maior remuneração sobre as aplicações de recursos na forma de depósitos na cooperativa.

Quadro 4 - Regressão Desempenho na Intermediação Financeira: Taxa de Juros sobre Depósitos

\begin{tabular}{lcccc}
\hline \multicolumn{1}{c}{ Variáveis } & Coeficiente & P-valor & Sinal & Sig. \\
\hline Constante & 0,161095 & $<0,0001$ & & $* * *$ \\
Capitalização & 0,0329965 & $<0,0001$ & + & $* * *$ \\
Imobilização & 0,0178827 & $<0,0001$ & + & $* * *$ \\
Captação por Floating & $-0,10889$ & $<0,0001$ & - & $* * *$ \\
Participação do Resultado de Outras Receitas & $-0,0543849$ & $<0,0001$ & - & $* * *$ \\
Operacionais & & & & \\
Eficiência Operacional & $-0,0228684$ & $<0,0001$ & - & $* * *$ \\
Margem Operacional & 0,0726487 & $<0,0001$ & + & $* * *$ \\
Captação por Depósitos a Prazo & $-0,0241461$ & $<0,0001$ & - & $* * *$ \\
Descasamento Passivo & $-0,0928804$ & $<0,0001$ & - & $* * *$ \\
Despesa Administrativa/Total Geral do Ativo & 0,218882 & $<0,0001$ & + & $* * *$ \\
Participação da Receita de Prestação de Serviços & $-0,0631656$ & $<0,0001$ & - & $* * *$ \\
R-quadrado & $\mathbf{0 , 6 0 0 0 8 8}$ & & & \\
P-valor(F) & $\mathbf{5 , 5 e - 2 9 8}$ & & & \\
N (quantidade de cooperativas) & $\mathbf{3 5 3}$ & & & \\
\hline
\end{tabular}

Fonte: Resultados da pesquisa

Verifica-se que a Capitalização, a Imobilização, a Margem Operacional e a Despesa Administrativa/Total Geral do Ativo apresentaram uma relação positiva com o aumento na taxa de juros sobre a captação de depósitos com cooperados. Tendo apresentado o sinal adequado em prol do beneficiamento dos cooperados, estes foram analisados como possíveis determinantes do desempenho na intermediação financeira e confirmados, conforme a análise apresentada a seguir.

O impacto da Capitalização sobre a variável (2) indica que a estrutura das cooperativas em termos de patrimônio líquido, devida à formação de reservas e pela retenção de ganhos e sua consequente melhor situação financeira, permite essa melhoria nas taxas que remuneram os cooperados pelas aplicações.

A relação da melhoria nas taxas oferecidas sobre depósitos com as Despesas Administrativas/Total Geral do Ativo pode estar relacionada ao fato de que maiores taxas atraem mais operações com cooperados, as quais exigem uma maior estrutura administrativa da cooperativa, o que também é válido para a Imobilização. 
O indicador de Margem Operacional utilizado reflete a relação ente o resultado operacional - decorrente das receitas não provenientes da atividade de intermediação financeira - e a receita total, podendo estar relacionado a um comportamento de diversificação das receitas. Sua relação positiva com a variável (2) pode indicar que a diversificação da receita impacta positivamente no aumento das taxas pagas pelos depósitos.

O Quadro 5, a seguir, apresenta os resultados da regressão a partir dos quais foram definidos os determinantes da variável (3). A variável Volume de Operações de Crédito com Cooperados deve ser analisada considerando que melhor será o desempenho da cooperativa quanto maior for seu valor, o qual indicaria mais operações de empréstimos e financiamentos com cooperados.

Quadro 5 - Regressão Desempenho na Intermediação Financeira: Volume de Operações de Crédito com Cooperados

\begin{tabular}{lcccc}
\hline \multicolumn{1}{c}{ Variáveis } & Coeficiente & P-valor & Sinal & Sig. \\
\hline Constante & 0,0697621 & $<0,0001$ & & $* * *$ \\
Aplicações em Tesouraria & $-0,212269$ & 0,0005 & - & $* * *$ \\
Participação do Resultado de Outras Receitas & $-0,0695744$ & $<0,0001$ & - & $* * *$ \\
Operacionais & & & & \\
Eficiência Operacional & 0,0261345 & $<0,0001$ & + & $* * *$ \\
Inadimplência & $-0,0239578<0,0001$ & - & $* * *$ \\
Insolvência & $-0,189153<0,0001$ & - & $* * *$ \\
Captação por Depósitos a Prazo & 0,046002 & $<0,0001$ & + & $* * *$ \\
Descasamento Passivo & $0,865781<0,0001$ & + & $* * *$ \\
Despesa Administrativa pelo Total Geral do Ativo & 2,88737 & $<0,0001$ & + & $* * *$ \\
Rentabilidade do Ativo & 1,39255 & $<0,0001$ & + & $* * *$ \\
Participação da Receita de Prestação de Serviços & $-0,183041$ & $<0,0001$ & - & $* * *$ \\
R-quadrado & $\mathbf{0 , 9 4 7 1 3 4}$ & & & \\
P-valor(F) & $\mathbf{0 , 0 0 0 0 0 0}$ & & & \\
N (quantidade de cooperativas) & $\mathbf{3 5 3}$ & & & \\
\hline
\end{tabular}

Fonte: Resultados da pesquisa

Os resultados indicam que o Volume de Operações de Crédito com Cooperados apresentou uma relação positiva com a Eficiência Operacional, com a Captação de Depósitos a Prazo, com o Descasamento Passivo, com a Despesa Administrativa/Total Geral do Ativo e com a Rentabilidade do Ativo. No entanto, após a análise dos resultados, apresentada a seguir, se mantiveram como determinantes apenas a Captação de Depósitos a Prazo, o Descasamento Passivo e a Despesa Administrativa/Total Geral do Ativo. 
O Descasamento Passivo, conforme explicitado, indica que as captações das cooperativas por meio de atos não cooperativos, aumentam o fornecimento de crédito, o que provavelmente ocorre devido à maior disponibilidade de recursos.

É natural também que, sendo os recursos dos poupadores a fonte de custo mais baixo para os recursos emprestados, um aumento na captação por depósitos a prazo reduza as taxas cobradas por empréstimos e, logo, gere aumentos no Volume de Operações de Crédito, o que justifica a significância da variável Captação por Depósitos a Prazo. Por outro lado, maiores volumes de operações de crédito também exigem uma maior estrutura administrativa da cooperativa, o que justifica aumentos na razão das despesas administrativas sobre o total geral do ativo, verificada também como determinante do desempenho na intermediação financeira.

Já os indicadores Eficiência Operacional e de Rentabilidade do Ativo, apesar de terem apresentado relação positiva significativa com a variável (3), ambos não foram confirmados como determinantes do desempenho na intermediação financeira. Quanto à Eficiência Operacional, neste caso, esta é que parece ser afetada pelo aumento nas operações de crédito, que potencialmente gera um aumento nas receitas e, logo, a capacidade de cobertura das despesas administrativas. O mesmo se aplica à Rentabilidade do Ativo, a qual é dependente do volume de operações de crédito fornecidas e das taxas oferecidas pelas cooperativas.

Os resultados da regressão para a variável (4) são apresentados no Quadro 6. Assim como a variável (3), o Volume de Captações de Depósitos também deve ser analisado considerando que a cooperativa terá um melhor desempenho quanto maior for seu valor, de modo que a organização realize mais operações de captação de depósitos por meio de atos cooperativos, favorecendo a geração de benefícios aos cooperados. 
Quadro 6 - Regressão Desempenho na Intermediação Financeira: Volume de Captações de Depósitos com Cooperados

\begin{tabular}{lcccc}
\hline \multicolumn{1}{c}{ Variáveis } & Coeficiente & P-valor & Sinal & Sig. \\
\hline Constante & 0,183369 & $<0,0001$ & & $* * *$ \\
Capitalização & $-0,208663$ & $<0,0001$ & - & $* * *$ \\
Imobilização & $-0,0561979$ & $<0,0001$ & - & $* * *$ \\
Eficiência Operacional & $-0,0277682$ & $<0,0001$ & - & $* * *$ \\
Margem Operacional & 0,0490426 & $<0,0001$ & + & $* * *$ \\
Captação por Depósitos a Prazo & 0,065801 & $<0,0001$ & + & $* * *$ \\
Despesa Administrativa/Ativo Total & 3,81923 & $<0,0001$ & + & $* * *$ \\
Rentabilidade do Ativo & 1,73647 & $<0,0001$ & + & $* * *$ \\
R-quadrado & $\mathbf{0 , 9 3 4 1 9 8}$ & & & \\
P-valor(F) & $\mathbf{0 , 0 0 0 0 0 0}$ & & & \\
N (quantidade de cooperativas) & $\mathbf{3 5 3}$ & & & \\
\hline
\end{tabular}

Fonte: Resultados da pesquisa

A Margem Operacional, a Captação por Depósitos a Prazo, a Despesa Administrativa/Ativo Total e a Rentabilidade do Ativo apresentam uma relação positiva com o aumento no Volume de Captações por Depósitos com Cooperados (4). Similar ao que ocorreu para a variável (3), após a análise dos resultados, apresentada a seguir, permaneceram como determinantes apenas a Despesa Administrativa/Total Geral do Ativo.

Observou-se, a partir dos resultados, que o Volume de Captações por Depósitos exige uma maior estrutura administrativa da cooperativa, o que justifica o aumento das Despesas Administrativas/Ativo Total e, portanto, a identificação desta como um determinante do desempenho.

Quanto às variáveis Margem Operacional e Rentabilidade do Ativo, apesar de terem apresentado uma relação positiva significativa com observa-se que na realidade a captação por depósitos com cooperados é que é um de seus determinantes e não o inverso, o que as descaracterizam como determinantes do desempenho das cooperativas, conforme indicado anteriormente.

Da mesma forma, apesar do sinal positivo significativo, a Captação por Depósitos a Prazo, não poderia ser caracterizada como uma determinante, visto que, na realidade, ela é o principal componente do indicador em questão, estando abarcada no capital de terceiros.

O Quadro 7, a seguir, apresenta os resultados das regressões para a variável (5), também relacionada ao desempenho das cooperativas na intermediação financeira. $\mathrm{O}$ 
Resultado Bruto da Intermediação Financeira, trará um melhor desempenho da cooperativa na geração de benefícios aos cooperados quanto maior for o seu valor, indicando capacidade de geração de sobras por meio da intermediação financeira.

Quadro 7 - Regressão Desempenho na Intermediação Financeira: Resultado Bruto da Intermediação Financeira/Ativo Total

\begin{tabular}{lcccc}
\hline \multicolumn{1}{c}{ Variáveis } & Coeficiente & P-valor Sinal & Sig. \\
\hline Constante & $-0,0121091$ & $<0,0001$ & & $* * *$ \\
Imobilização & 0,0030852 & 0,0025 & + & $* * *$ \\
Participação do Resultado de Outras Receitas & $-0,0174722<0,0001$ & - & $* * *$ \\
Operacionais & & & & \\
Eficiência Operacional & 0,0170609 & $<0,0001$ & + & $* * *$ \\
Insolvência & $0,0270948<0,0001$ & + & $* * *$ \\
Despesa Administrativa/Total Geral do Ativo & $0,944032<0,0001+$ & $* * *$ \\
Rentabilidade do Ativo & $0,193536<0,0001+$ & $* * *$ \\
Participação da Receita de Prestação de Serviços & $-0,0733043<0,0001$ & - & $* * *$ \\
R-quadrado & 0,963534 & & & \\
P-valor(F) & 0,000000 & & & \\
N (quantidade de cooperativas) & $\mathbf{3 5 3}$ \\
\hline
\end{tabular}

Verificou-se que as apresentaram uma relação positiva com o Resultado Bruto da Intermediação Financeira/Ativo Total (5), os seguintes indicadores: Imobilização, Eficiência Operacional, Insolvência, Despesa Administrativa/Total Geral do Ativo e Rentabilidade do Ativo. Após a análise, no entanto, foram descartados os indicadores Rentabilidade do Ativo e Eficiência Operacional como determinantes, já que estes têm a mesma natureza (indicadores de resultado) da proxy em questão.

O resultado encontrado para a Imobilização é reflexo da estrutura de ativos fixos das cooperativas, a qual, potencialmente, permite operações com custos mais baixos e que gerem, portanto, um maior resultado. Ressalta-se que o Resultado Bruto da Intermediação Financeira decorre principalmente do resultado das rendas de operações de crédito, de aplicações interfinanceiras de liquidez e com títulos e valores mobiliários e instrumentos financeiros derivativos e das despesas relacionadas.

Por outro lado, a relação do Resultado Bruto da Intermediação Financeira com as Despesas Administrativas/Ativo Total decorre da maior exigência de uma estrutura administrativa da cooperativa para a geração de maiores resultados. Já no que tange ao indicador Insolvência, seu resultado indica que as operações de mais alto risco geram maiores resultados para a cooperativa. 
Na subseção 4.2 são apresentados os resultados dos determinantes do desempenho na prestação de serviços.

\subsection{Determinantes do desempenho na prestação de serviços}

A avaliação do desempenho na prestação de serviços sugerida neste trabalho utiliza como única variável dependente a Participação da Receita de Prestação de Serviços (6).

$\mathrm{Na}$ análise das regressões com dados em painel verificou-se que foram rejeitadas as hipóteses nulas dos testes de Chow, de Breusch-Pagan e de Hausman. Assim como no modelo de intermediação financeira, verificou-se a como mais adequada a utilização do modelo de efeitos fixos.

A variável Participação da Receita de Prestação de Serviços deve ser analisada considerando que a cooperativa terá um melhor desempenho quanto maior for o seu valor, o qual indicaria um melhor cumprimento de sua finalidade de prestar serviços bancários, gerando maior benefício aos cooperados, os quais teriam menor dependência de outras instituições financeiras.

O Quadro 8, a seguir, apresenta os resultados da regressão para a variável (6).

Quadro 8 - Regressão Desempenho na Prestação de Serviços: Participação da Receita de Prestação de Serviços

\begin{tabular}{lcccc}
\hline \multicolumn{1}{c}{ Variáveis } & Coeficiente & P-valor & Sinal & Sig. \\
\hline Constante & 0,235379 & $<0,0001$ & & $* * *$ \\
Imobilização & $0,042498<0,0001$ & + & $* * *$ \\
Captação por Floating & $0,072994<0,0001$ & + & $* * *$ \\
Participação do Resultado de Outras Receitas & $-0,223693<0,0001$ & - & $* * *$ \\
Operacionais & & & & \\
Eficiência Operacional & $-0,0299022<0,0001$ & - & $* * *$ \\
Margem Operacional & $0,147049<0,0001$ & + & $* * *$ \\
Despesa Administrativa pelo Total Geral do & $0,803892<0,0001$ & + & $* * *$ \\
Ativo & $-0,466562<0,0001$ & - & $* * *$ \\
Rentabilidade do Ativo & $-0,154077<0,0001$ & - & $* * *$ \\
Taxa de Juros sobre Depósitos & $-0,0896639<0,0001$ & - & $* * *$ \\
Taxa de Juros sobre Empréstimos & $\mathbf{0 , 8 5 9 7 6 7}$ & & \\
R-quadrado & $\mathbf{0 , 0 0 0 0 0 0}$ & & & \\
P-valor(F) & $\mathbf{3 5 3}$ \\
N (quantidade de cooperativas) & \multicolumn{2}{c}{ Fonte: Resultados da pesquisa } \\
\hline
\end{tabular}


Verifica-se que a Imobilização, a Captação por Floating, e as Despesas Administrativas/Ativo Total estão positivamente relacionadas com a Participação da Receita de Prestação de Serviços no total de receitas da cooperativa. As três variáveis são indicadas como determinantes do desempenho na prestação de serviços. Já a Margem Operacional, nota-se por sua composição que na verdade a mesma é afetada pela Participação da Receita de Prestação de Serviços, e não o contrário, de modo que a primeira não foi considerada como determinante do desempenho.

O resultado para a Imobilização indica que uma maior Participação da Receita de Prestação de Serviços na receita total requer maior investimento em ativos permanentes. Já a Captação por Floating, relacionada aos passivos sem encargos da cooperativa (Depósitos a Vista e Cobrança e Arrecadação de Tributos e Assemelhados), também afetam positivamente a variável, o que provavelmente está relacionado ao fato de as rendas com depósitos a vista e rendas de cobrança estarem inclusas na conta "rendas de serviços prioritários - PF" do plano de contas detalhado, a qual também compõe a conta "renda de prestação de serviçoo".

Com relação às Despesas Administrativas/Total Geral do Ativo, como foi visto, a prestação de serviços não geradores de juros exige uma maior estrutura administrativa da cooperativa, principalmente no que tange ao aumento das despesas com pessoal, o que justifica o resultado.

\subsection{Análise Abrangente dos Resultados}

Nas subseções 4.2 e 4.3 foram apresentados os resultados das regressões com dados em painel para cada variável representativa do desempenho das cooperativas de crédito na geração de benefícios aos cooperados. Pelos resultados, verificou-se que alguns dos determinantes são comuns a mais de uma variável, o que inicialmente pode demonstrar quais são os fatores aos quais deve ser dada maior atenção quando da estruturação e administração dessas organizações.

A partir dos resultados das regressões e das interpretações apresentadas, o Quadro 9 resume as variáveis determinantes do desempenho nos modelos de intermediação financeira e de prestação de serviços bancários. 
Quadro 9 - Determinantes do desempenho nos modelos de intermediação financeira e de prestação de serviços

\begin{tabular}{l|c|c|c|c|c|c}
\hline \multirow{2}{*}{ Determinantes do desempenho } & \multicolumn{6}{c}{ Variáveis de desempenho } \\
\cline { 2 - 7 } & \multicolumn{5}{c}{ Intermediação } & \multicolumn{1}{c}{$\begin{array}{c}\text { Prestação } \\
\text { de Serviços }\end{array}$} \\
\hline & $\mathbf{1}$ & $\mathbf{2}$ & $\mathbf{3}$ & $\mathbf{4}$ & $\mathbf{5}$ & $\mathbf{6}$ \\
\hline Capitalização & & $\mathrm{X}$ & & & & \\
\hline Participação do Resultado de Outras Receitas Operacionais & $\mathrm{X}$ & & & & & \\
\hline Eficiência Operacional & & & & & & \\
\hline Margem Operacional & & $\mathrm{X}$ & & & & \\
\hline Insolvência & & & & & $\mathrm{X}$ & \\
\hline Descasamento Passivo & $\mathrm{X}$ & & $\mathrm{X}$ & & & \\
\hline Participação da Receita de Prestação de Serviços & $\mathrm{X}$ & & & & & \\
\hline Despesas Administrativas/Total Geral do Ativo & & $\mathrm{X}$ & $\mathrm{X}$ & $\mathrm{X}$ & $\mathrm{X}$ & $\mathrm{X}$ \\
\hline Imobilização & & $\mathrm{X}$ & & & $\mathrm{X}$ & $\mathrm{X}$ \\
\hline Captação por Floating & & & & & & $\mathrm{X}$ \\
\hline Legena
\end{tabular}

Legenda: 1 - Taxa de Juros sobre Empréstimos; 2 -Taxa de Juros sobre Depósitos; 3 - Volume de Operações de Crédito com Cooperados; 4 - Volume de Captações por Depósitos com Cooperados; 5 - Resultado Bruto da Intermediação Financeira/Total Geral do Ativo; 6 - Participação da Receita de Prestação de Serviços

Fonte: Resultados da Pesquisa

Conforme apresentado no Quadro 9, são determinantes do desempenho das cooperativas de crédito na atividade de intermediação financeira as variáveis: Capitalização, Participação do Resultado de Outras Receitas Operacionais, Margem Operacional, Insolvência, Descasamento Passivo, Participação da Receita de Prestação de Serviços, Despesas Administrativas/Total Geral do Ativo e Imobilização. Já na atividade de prestação de serviços, são determinantes as variáveis Despesas Administrativas/Total Geral do Ativo, Imobilização e Captação por Floating.

Observe que os resultados apresentados nos Quadros 3 e 5 mostram o indicador Captação por Depósitos a Prazo como significativo a 99\% para as variáveis Taxa de Juros sobre Empréstimos e Volume de Operações de Crédito com Cooperados. No entanto, considerando o modelo como um todo e relembrando que a abordagem adotada no presente trabalho foi a de prestação de serviços, a qual considera os depósitos como um produto gerado pela cooperativa em benefício dos cooperados, essa variável não permanece como determinante no modelo final.

Verifica-se pelos resultados que é interessante que uma cooperativa que atue buscando aumentar as taxas pagas pelos depósitos de cooperados se atente para o índice de capitalização, visto que este é considerado um determinante neste objetivo. Há de se 
observar, no Quadro 6, que o aumento no indicador tem um impacto negativo sobre o volume de captações de depósitos com cooperados. Este resultado não era esperado, já que de um aumento nas taxas pagas em retorno aos depósitos, o qual é influenciado pela Capitalização, se esperaria um aumento da demanda pelo serviço de poupança.

Enquanto isso, a Imobilização favorece, não somente maiores taxas de juros pagas pelos depósitos e a geração do resultado bruto da intermediação financeira, mas também é determinante no desempenho na prestação de serviços bancários.

Ainda, verificou-se a Participação da Receita de Prestação de Serviços e a Participação do Resultado de Outras Receitas Operacionais contribuem para uma redução nas taxas de juros sobre empréstimos e, portanto, para uma potencial redução no Spread das cooperativas. Essa análise é relevante pois espera-se que, em relação às demais instituições financeiras, espera-se que uma cooperativa de crédito ofereça taxas mais vantajosas no oferecimento de crédito e remunere os cooperados a taxas mais altas pela aplicação de recursos.

É inevitável, ainda, atentar para a importância dos resultados do indicador despesas administrativas/ativo total. Os resultados mostram que essas despesas são determinantes na geração de praticamente todos os produtos fornecidos pelas cooperativas, não tendo sido significativas apenas para a variável Taxa de Juros sobre Empréstimos. Isso mostra que a gestão desse recurso pode ser fundamental na atuação eficiente das cooperativas de crédito.

Quanto ao indicador de Descasamento Passivo, é possível notar que, sendo uma fonte de captação, este é, também, uma fonte para o fornecimento de mais empréstimos. Enquanto o Descasamento Passivo favorece reduções nas Taxas de Juros sobre Empréstimos e aumentos no Volume de Operações de Crédito com Cooperados, ele também determina uma redução nas Taxas de Juros sobre Depósitos (ver Quadro 5), o que já não é favorável aos cooperados. Esse fato chama a atenção para um fator visível no Quadro 3, de que os fatores determinantes de taxas de juros sobre empréstimos favoráveis aos cooperados e de aumentos no volume de operações de crédito não são compatíveis com os determinantes de taxas de juros sobre depósitos mais altas, ou seja, haveria inicialmente uma dificuldade de conciliação dos objetivos da organização.

Por último, merece ser dada atenção para o fato de que as duas variáveis determinantes do modelo de prestação de serviços, as Despesas Administrativas/Total 


\section{Revista

Geral do Ativo e a Imobilização, também são determinantes do modelo de intermediação financeira, o que indica, inicialmente, a capacidade de melhoria no desempenho nas duas vertentes investigadas a partir de determinantes comuns.

\section{Considerações Finais}

No sentido de contribuir com as pesquisas que avaliam as cooperativas de crédito quanto à sua atividade, esta pesquisa investigou os determinantes do desempenho das cooperativas de crédito brasileiras diante de seu objetivo de beneficiar economicamente o cooperado.

A principal contribuição desta pesquisa é a avaliação do desempenho das cooperativas de crédito brasileiras sob dois aspectos diferentes, ambos os quais consideram a perspectiva do cooperado, e que sugeririam uma avaliação de desempenho com base em dois modelos. O primeiro aspecto, que daria origem a um primeiro modelo, considera a atividade de intermediação financeira, atividade principal desse tipo de organização. O segundo aspecto, que originaria um segundo modelo, considera a atividade de prestação de serviços bancários, os quais também beneficiam cooperados.

Quanto aos resultados apresentados, destaca-se que a discordância dos efeitos de algumas das variáveis determinantes identificadas sobre as variáveis dependentes pode, em algum momento, justificar comportamentos de dominação em cooperativas de crédito explorados pela literatura.

O trabalho apresenta como principais limitações a não utilização de variáveis não contábeis que poderiam ser significativas na avaliação do desempenho operacional e financeiro, como o número de cooperados das organizações, devido à falta de acesso a tais dados. Além disso, os dados pouco discriminados em relação a abertura de contas do banco de dados utilizado podem ser afirmados também como uma limitação.

Reforça-se a importância de se conhecer os determinantes de desempenho das cooperativas de crédito, o que poderia permitir aos gestores, em nível institucional, promover ações que busquem uma melhoria na performance do beneficiamento dos cooperados por meio do impacto gerado em sua renda, já que este é o objetivo principal em prol do qual a cooperativa de crédito deve atuar e pelo qual estas surgem.

\section{Referências}


Barton, D. (1989). What is a cooperative? In D. W. Cobia (1989). Cooperatives in Agribusiness, Nova Jersey: Regents/Prentice Hall, 1-20.

Bauer, K. (2008). Detecting abnormal credit union performance. Journal of Banking and Finance, 32(edição), 573-586.

Bressan, V. G. F (2009). Seguro Depósito e Moral Hazard nas cooperativas de crédito brasileiras. Universidade Federal de Viçosa, MG.

Bressan, V. G. F., Braga, M. J., e Bressan, A. A. (2010). Eficiência e economia de escala em cooperativas de crédito: uma abordagem de fronteira estocástica de custo com dados em painel. Advances in Specific and Applied Accounting, 3(3), 335-352.

Bressan, V. G. F., Braga, M. J., Bressan, A. A., \& Resende Filho, M. de A. (2011). Avaliação de insolvência em cooperativas de crédito: uma aplicação do Sistema Pearls. Revista de Administração Mackenzie, 12(2), p. 113-144.

Cook, W.D.; Bala, K. 2007. Performance measurement and classification data in DEA: Input-oriented model. Omega, 35(1): 39-52.

Fávero, L. P.; Belfiore, P.; Silva, F. L.; Chan, B. L. (2009). Análise de dados: modelagem multivariada para tomada de decisões. Rio de Janeiro: Elsevier-Campus.

Ferreira, M. A. M.; Gonçalves, R. M. L.; Braga, M. J. (2007). Investigação do desempenho das cooperativas de crédito de Minas Gerais por meio da Análise Envoltória de Dados (DEA). Economia Aplicada, 11(3): 425-445.

Frame, W. S., Karels, G. V., Mcclatchey C. A. (2003). Do credit unions use their tax advantage to benefit members? Evidence from a cost function. Review of Financial Economics 12(2003): 35-47.

Fried, H. O.; Lovell, C.A. K.; Eeckaut, P. V. (1993). Evaluating the performance of U.S. credit unions. Journal of Banking and Finance, 17, p. 251-265.

Glass, J.C.; Mckillop, D.G.; Rasaratnam, S. (2010). Irish credit unions: investigating performance determinants and the opportunity cost of regulatory compliance. Journal of Banking and Finance, 34(2010): 67-76.

Goddard, J.; McKillop, D.; Wilson, J. O.S. (2008). The diversification and financial performance of US credit unions. Journal of Banking \& Finance, 32, p. 18361849.

Matias, A. B.; Quaglio, G. M..; Lima, J. P. R.; Magnani, V. M. (2014). Bancos versus cooperativas de crédito: um estudo dos índices de eficiência e receitas da prestação de serviços entre 2002 e 2012. RAM, Rev. Adm. Mackenzie 15(5), p.195-223.

McKillop, D.; Wilson, J. O. S. (2011). Credit Unions: a theoretical and empirical overview. Financial Markets, Institutions \& Instruments, 20, Issue 3, pp. 79-123.

Rubin, G. M., Overstreet Jr. G. A., Beling, P., Rajaratnam, K. (2013). A dynamic theory of the credit union. Annals of Operations Research, 205(1), 29-53.

Santos, A. A. (2013). Estudo das características da população de cooperados. In: Fórum Banco Central sobre Inclusão Financeira, V, Fortaleza, 2013. Fortaleza, 1-17. 


\section{Contabilidade}

Silva, T. P.; Gollo, V.; Junior, M. M. R. (2013) Análise da Eficiência na Atividade de Concessão de Crédito em Cooperativas Brasileiras. XXIV ENANGRAD. FIN Finanças. Florianopolis.

Smith, D. J.; Cargill, T. F.; Meyer, R. A. (1981). Credit unions: an economic theory of a credit union. The Journal of Finance, 36, 519-528.

Taylor, R. A. (1971). The credit union as a cooperative institution. Review of Social Economy, 29(2), 208-217.

Vilela, D. L.; Nagano, M. S.; Merlo, E. M. (2007). Aplicação da análise envoltória de dados em cooperativas de crédito rural. Rev. Adm. Contemp., v. 11, n. spe2.

Wheelock, D. C.; Wilson, P. W. (2013). The Evolution of Cost-Productivity and Efficiency Among US Credit Unions. Journal of Banking and Finance, 37, 7588.

Wooldridge, J. M. (2008). Introdução à Econometria: Uma Abordagem Moderna. São Paulo: Cengage Learning. 